\title{
Research on Engineering Geomechanics Characteristics and CFRP Reinforcement Technology Based on Machine Learning Algorithms
}

\author{
Baoqi Yan (D), ${ }^{1}$ Nuoya Zhang, ${ }^{1}$ Ganggang Lu, ${ }^{1,2}$ and Yue Hui ${ }^{1}$ \\ ${ }^{1}$ Chang'an University, School of Civil Engineering, Xi'an, Shaanxi 710064, China \\ ${ }^{2}$ China Northwest Architecture Design and Research Institute Co., Ltd, Xi'an, Shaanxi 710018, China \\ Correspondence should be addressed to Baoqi Yan; 2018128055@chd.edu.cn
}

Received 11 October 2021; Revised 1 November 2021; Accepted 5 November 2021; Published 7 January 2022

Academic Editor: Bai Yuan Ding

Copyright (c) 2022 Baoqi Yan et al. This is an open access article distributed under the Creative Commons Attribution License, which permits unrestricted use, distribution, and reproduction in any medium, provided the original work is properly cited.

We have completed the design of an early warning and evaluation analysis module based on machine learning algorithms. Aiming at the prestressed CFRP-strengthened reinforced concrete bridges under natural exposure, we developed a theoretical model to analyze the long-term prestress loss of reinforced parts and the adhesion behavior of the CFRP-concrete interface under natural exposure conditions. The analysis deeply reveals the technical and engineering geomechanics characteristics of the D bridge. At the same time, through a series of experimental studies on the D bridge condition monitoring system, the data acquisition and transmission, processing and control of the $\mathrm{D}$ bridge condition monitoring system, and the bridge condition monitoring and evaluation software are provided. Regarding how to repair the engineering geomechanical characteristics of D bridge, we mentioned the prestressed CFRP reinforcement technology. The prestressed carbon fiber reinforced composite (CFRP) structure made of reinforced concrete (RC) makes better use of the high-strength characteristics of CFRP and changes. It strengthens the stress distribution of the components and improves the overall strength of the components. It is more supported by engineers in the civil engineering and transportation departments. However, most prestressed CFRP-reinforced RC structures are located in natural exposure environments, and the effect of natural exposure environments on the long-term mechanical properties of prestressed C FRP-reinforced RC components is still unclear. This article mainly uses the research on the engineering geomechanics characteristics and reinforcement technology of the bridge body, so that people have a deep understanding of its concept, and provides reasonable use methods and measures for the maintenance and protection of the bridge body in the future. This paper studies the characteristics of engineering geomechanics based on machine learning algorithms and applies them to the research of CFRP reinforcement technology, aiming to promote its better development.

\section{Introduction}

Since the 1990s, machine learning algorithms have gradually been applied to the study of geomechanical properties of bridge construction and related research on the properties of damaged parts of bridges [1]. The engineering geomechanical characteristic data of the bridge damage is sent to the machine, and the machine uses the learning algorithm calculation and pattern recognition to complete the work on the damage site [2]. The identification of the damage program can be traced back to the problem of functional adaptation [3]. The machine learning algorithm learns from historical data to set the geoengineering features of different damage degree projects and adapts the appropriate feature plane to the special space where the feature data is sent to the machine learning algorithm [4]. The learning algorithm calculates the data on the surface of the corresponding feature and then performs interpolation to evaluate the degree of damage, and it plays a leading role in the repair of the bridge [5]. Due to the repeated action of the alternating load of the bridge, the maximum stress that the concrete bridge bears does not reach the allowable stress of the static strength design [6]. Fatigue cracks are generated at the local positions of the concrete members and propagate, and 
finally, fatigue fracture will occur. It brings greater safety and social risks, and its maintenance also brings a huge economic burden, which brings great troubles to people's travel convenience [7]. Studies have shown that the cost of building a new bridge is relatively high, and the cost of strengthening a bridge is at least $10 \%$ of the cost of a new bridge. Relatively speaking, it is cheaper and more efficient to use reinforcement or repair instead of new construction [8]. Therefore, this article will focus on the research of carbon fiber reinforced composite material (CFRP) paste reinforcement technology to explore whether the engineering geomechanical properties of the damaged bridge can be restored [9]. At present, engineering practice and a number of research results show that prestressed CFRP reinforcement technology, as an active reinforcement technology, significantly improves the utilization efficiency of CFRP, provides a more convenient and efficient use plan for the application of CFPR, and makes better use of it [10]. The strength advantage lays a solid foundation for a wider range of applications. It can participate in the force (effective force) before the reinforced component is subjected to the second force, and the stress distribution of the reinforcing element can be changed to close the original crack or prevent its expansion [11]. Therefore, the prestressed CFRP reinforcement technology is more and more favored by traffic and civil engineers [12]. The use of prestressed CFRP reinforcement technology has become widespread in practice. Under actual operating conditions, the long-term mechanical properties of prestressed CFRP-reinforced concrete (RC) components have also attracted more and more attention, and they have been more and more used in various applications [13]. This kind of machinery played a greater role in the practice process.

\section{Materials and Methods}

\subsection{Research Objects}

2.1.1. Introduction to the Example Test. After the fatigue test of the reinforced concrete beam by the Structural Laboratory of Chang'an University, the fatigue test was analyzed by finite element simulation ABAQUS. Three typical long-span bridges are selected as representatives: Bridge A, Bridge B, and Bridge $C$. These were originally built in certain urban areas and are still in operation and are calculated by Midas Civil 2012 software. Then, based on the "Specifications for Design of Concrete Structures", the fatigue stress calculations of the three small and medium-sized bridges were confirmed, and the stress levels of the vertical steel bars under the design load of the three bridges were investigated to be 0.5 and 0.55 , respectively [14]. The minimum stress level under load is 0.25 .

2.1.2. Selection of Material Parameters. (1) According to concrete reference materials, all concrete beams in the fatigue simulation test of this study are made of C40 concrete.

(2) In the rod fatigue simulation test, the strength grade of the rod is HRB400.
2.1.3. Design of Test Beam Conditions. It has 3 test strips, which can be divided into 2 groups. One group is the static load test, which measures the maximum load-bearing bending moment $\mathrm{Mu}$ of the concrete beam and determines the upper and lower limits of fatigue according to the stress level required by the fatigue test [15]. The other group is the test beam fatigue test.

\subsection{Theoretical Basis}

\subsubsection{Early Warning Assessment of Long-Span Bridge} Damage. In recent years, the overall structural condition monitoring technology based on vibration testing and modal analysis has been relatively mature in the machinery and aerospace industries. After the early warning method is used to determine the damage of the long-span bridge, the test mode analysis should be used to further diagnose the location and extent of the structural damage in order to monitor the long-span bridge structure [16] and provide basis and guidance for system identification, structure evaluation, and decision-making for maintenance and repair managers [17]. This content can be summarized as an early warning assessment of remote bridge damage. According to engineering data, D bridge's 3D benchmark finite element model has 11 elements and 10 nodes. Damage analysis allows us to select 10 nodes as damage objects. In the $(x, y)$ quadrant along the $x$-direction, there are 1 to 10 nodes in turn. 10 nodes with different damage levels $(5 \%-100 \%)$ can get 200 groups of damage conditions. The 200 damage conditions are divided into 20 condition groups, and each condition group has 26 damage conditions. Concerning the damage to 10 nodes numbered 1-10, the damage degree of each working condition group gradually increases. After a series of calculations, the influence of the location and damage degree of each node on the natural frequency of the bridge can be determined. This paper normalizes the natural frequencies of each damage condition group based on normal data.

$$
\bar{f}_{i j k}=\frac{f_{i i k}}{f_{i 0}}, \quad i=1,2, \ldots, 10 ; j=1,2, \ldots, 20 ; k=1,2, \ldots, 10 .
$$

In the formula, $f_{i j k}$ represents the $i$-th natural frequency of the $j$-th operating condition group and the $k$-th operating condition (dimension) normalized by data. The $k$-th working state is represented by $f_{i j k}$. There is an $i$-th natural vibration value $(\mathrm{Hz})$ of the $j$-th working condition group before data normalization. $f_{\mathrm{i} 0}$ represents the $i$-th natural vibration value $(\mathrm{Hz})$ without damage.

2.2.2. Neural Network Method. Since the 1990s, neural networks have gradually been used in bridge research to identify structural damage. For some applications, only injury data from injury condition group 1 ( $5 \%$ injury) is used as the training set and sent to the neural network for training. We understand the distribution function between the damage location and the natural frequencies of each order. If a knot is damaged, even if the actual damage is 
different from the training conditions, the damage will not have a significant impact on the above [18]. For the mentioned mapping feature and damage feature sensitive positioning factors, the neural network can identify the actual damage location according to the natural frequency distribution of each order in the multidimensional space. The specific process is as follows:

$$
e_{k}(n)=d_{k}(n)-y_{k}(n) .
$$

We define the total energy function of the network as follows:

$$
E_{n}(n)=\frac{1}{2} \sum_{k} e_{k}^{2}(n)
$$

The network feedforward process is as follows:

$$
\begin{aligned}
v_{j}(n) & =\sum_{i} \omega_{j i}(n) y_{i}(n), \\
y_{j}(n) & =f\left(v_{j}(n)\right), \\
v_{k}(n) & =\sum_{j} \omega_{k j}(n) y_{j}(n), \\
y_{k}(n) & =f\left(v_{k}(n)\right) .
\end{aligned}
$$

The reverse calculation process of the network can be obtained:

$$
\frac{\partial E(n)}{\partial \omega_{j i}(n)}=\left[-\sum_{k} \delta_{k}(n) \omega_{k j}(n)\right] f^{\prime}\left(v_{j}(n)\right) y_{i}(n) .
$$

Then, the weight correction amount of the hidden layer unit is

$$
\begin{aligned}
\Delta w_{j i}(n) & =\eta \delta_{j}(n) y_{i}(n), \\
\omega_{j i}(n+1) & =\omega_{j i}(n)+\Delta \omega_{j i}(n) \\
& =\omega_{j i}(n)+\eta \delta_{j}(n) y_{i}(n) .
\end{aligned}
$$

\subsection{Research Methods}

2.3.1. Mechanical Analysis Corresponding to Rigid Body Displacement at Structural Level. The rigid body displacement of the structural plane usually includes the lateral displacement, the longitudinal displacement, the vertical displacement, and the rotation around the vertical, horizontal, and vertical axes of the entire structure. The rigid body displacement at the structural level is the same spatial change in the entire structure at the same time, so whether it is a statically indeterminate structure or a statically indeterminate structure, the rigid body displacement at the structural level will not generate force. The displacement of the rigid body at the structural level does not produce any force on the structure, so it is not always subject to force when the structure moves. In the case of rigid body displacement at the structural level when the bridge space changes, the force cannot be equal to the space deformation and the stress state cannot be derived from the bridge space deformation. If the structure-level rigid body displacement is not distinguished, but the structure-level rigid body displacement and the component-level displacement are mixed and the mechanical state is analyzed, the force state can be obtained from the analysis of the mixed space. In this process, the shape change is inaccurate because it is assumed that the displacement of the rigid body can exert pressure on the structure at the structural level. Therefore, before the analysis of mechanical properties, structural rigid body displacement analysis is required to identify and eliminate the total rigid body displacement of the structure.

\subsubsection{Mechanical Analysis Corresponding to Rigid Body} Displacement at Component Level. The component-level rigid body displacement analysis is usually based on the structural-level rigid body displacement analysis. The rigid body displacement of the component usually includes the lateral displacement, vertical displacement, and deflection of the component. For statically indeterminate structures, the rigid body displacement at the component level will not produce a force on the component, but for statically indeterminate structures, the rigid body displacement of the component causes the component to receive minor internal forces. In the statically determinate structure of the rod, if there is no rigid body displacement at the rod level, the deformation shape includes the rigid body deformation of the entire rod, and the rigid body deformation of the entire rod will not affect the force of the member. Rigid body displacement analysis is used to identify and eliminate the total rigid body displacement of the component to obtain an accurate force state. For components with a statically indeterminate structure, the displacement of the rigid body at the component level will cause the component to generate secondary internal forces. The force state of the component can be calculated by adding the rigid body displacement obtained at the structural level to the force displacement, using the finite element model of the component.

\subsubsection{Mechanical Analysis Corresponding to Changes in the} Internal Space of Components. The internal deformation analysis of the component is usually based on the rigid body displacement analysis at the structural level and the rigid body displacement analysis at the component level. Deformation of the interior of a part usually includes vertical bending, horizontal bending, and twisting. From the change of the vertical bending moment of the member along the horizontal direction of the bridge, the change of the vertical bending moment of the member can be obtained, so as to determine the direction of the change of the vertical bending moment; the transverse bending change of the steel bar in the longitudinal direction of the bridge receives the change of the transverse bending moment. We determine the direction of lateral bending moment change. Changing the torsion of the rod changes the torque received by the rod and determines the direction of the torque.

2.4. Experimental Protocol. The experimental method to study the behavior of the FRP-concrete interface is the pull- 
out test. There are three common types; single shear test, double-shear test, and bending test are all causal pull-out tests. The FRP termination is poorly peeled. The advantage of a simple shear test is that it is easy to handle, but it is very difficult to meet the final load level and may cause an eccentric load. Although the double-shear test can overcome the shortcomings of eccentric load, most concrete structures are in a bent state, and the double-shear test cannot fully simulate the actual situation of GRP reinforced concrete members. In this chapter, we choose the bending test as the experimental method to study the interface behavior of FRP concrete. In this experiment, a total of 6 samples with exposure times of 0,180 , and 360 days were tested. Table 1 shows the mechanical properties of the main materials in the experiment.

The specimen consists of two RC elements with a length of $300 \mathrm{~mm}$ and a cross-sectional dimension of $100 \mathrm{~mm} \times 150 \mathrm{~mm}$. The two concrete members are connected by two HRB hot-rolled ribbed steel bars with a length of $650 \mathrm{~mm}$ and a diameter of $\Phi 12$, leaving a gap of $10 \mathrm{~mm}$ between the two concrete members. Considering various effective bonding lengths, the maximum effective length of the test piece is $109 \mathrm{~mm}$. Therefore, a GRP adhesive with a length of $150 \mathrm{~mm}$ is selected, and a GRP board with a size of $50 \mathrm{~mm} \times 310 \mathrm{~mm}$ is attached from the outside on the underside of the sample. On the other side, a $200 \mathrm{~mm} \times 600 \mathrm{~mm}$ FRP board is wrapped for shear reinforcement to ensure that peeling occurs first.

In this work, a 4-point bending test was carried out. Therefore, all samples were loaded into a hydraulic press with a capacity of $500 \mathrm{kN}$, and the path-controlled monotonic loading method was used to load the two-point loading system. The distance between the two load points and the two supports is $100 \mathrm{~mm}$ or $310 \mathrm{~mm}$, and a monotonic load occurs at a constant speed of $0.2 \mathrm{~mm} / \mathrm{min}$. The force sensor is connected to the two loading heads and records the applied load. For each test, a linear variable differential sensor (LVDT) with a measuring range of $50 \mathrm{~mm}$ and an accuracy of $0.01 \mathrm{~mm}$ is placed in the center of the span to measure the deflection of the test piece. In order to record the strain of FRP, a total of 8 strain gauges were installed at a distance of $20 \mathrm{~mm}$ outside the entire length of FRP, and the static strain gauge automatically recorded the strain value of the entire test. Before the formal application, the test piece should be pretensioned to check the operating condition of the machine and reduce the gap between the load head and the test piece.

The results of the bending test of the test samples show the bonding behavior of the interface between the FRP and the concrete while considering the influence of the FRP type and exposure time, including the peeling load, the fracture mode, and the FRP load under various loads. As shown in Table 2, the final stresses of the specimens after exposure to the subtropical natural environment for 0 days, 180 days, and 360 days.

The way the sample breaks is to peel the FRP from the interface and place concrete in various thicknesses. When poor peeling occurs, there is a slight cracking sound in the middle of the span. As the load increases, the surface of the
TABLE 1: Main material parameters.

\begin{tabular}{lcc}
\hline Material & \multicolumn{1}{c}{ Material parameters } \\
\hline & Tensile strength/MPa & 4133 \\
CFRP board & Elastic modulus/GPa & 230 \\
& Elongation/\% & 1.88 \\
& Thickness/mm & 0.168 \\
\hline & Tensile strength/MPa & 2101 \\
BFRP board & Elastic modulus/GPa & 90 \\
& Elongation/\% & 2.5 \\
& Thickness/mm & 0.110 \\
\hline \multirow{3}{*}{ Adhesive } & Tensile strength/MPa & 49 \\
& Elastic modulus/GPa & 2.379 \\
\hline Concrete & Elongation/\% & 1.9 \\
\hline
\end{tabular}

Table 2: Experimental results of test pieces.

\begin{tabular}{lccc}
\hline Specimen number & FRP type & Exposure time/d & Peeling load/kN \\
\hline CFRP-0 & & 0 & 36.65 \\
N-CFRP-180 & CFRP & 180 & 31.65 \\
N-CFRP-360 & & 360 & 32.97 \\
\hline BFRP-0 & & 0 & 22.31 \\
N-BFRP-180 & BFRP & 180 & 16.33 \\
N-BFRP-360 & & 360 & 16.63 \\
\hline
\end{tabular}

concrete will begin to crack, producing a cracking sound, and eventually, the FRP will peel off the concrete. Compared with the control sample, the fracture mode of the CFRP sample is the shear fracture and delamination of the concrete, while the BFRP sample is the FRP directly peeled from the concrete. Generally, the damage of the specimen exposed to the natural environment is the peeling damage at the interface between FRP and concrete. In a naturally exposed environment, rainwater directly penetrates into the adhesive layer, and the adhesive layer is more sensitive to moisture, thereby reducing the shear strength of the adhesive layer interface. It can be seen that whether it is the CFRP-concrete interface or BFRP-concrete interface, their adhesion properties deteriorate with the increase of exposure time.

\section{Results}

\subsection{Analysis of Dead Weight and Dead Load Effect of Engineering Geomechanics}

3.1.1. The Dead Weight Effect. In the case of a straight beam bridge, the influence of its own weight is generally only vertical displacement, but in the case of a curved beam bridge, the center of gravity of its own weight moves to the outside of the curve, and there is an eccentric distance from the axis. This study uses the finite element model simulation method to calculate the displacement of the D bridge under its own weight and dead load, as shown in Figure 1. This study defines the following: the vertical displacement upward is positive, downward is negative, the lateral displacement of the curved bridge is positive, and the inward 


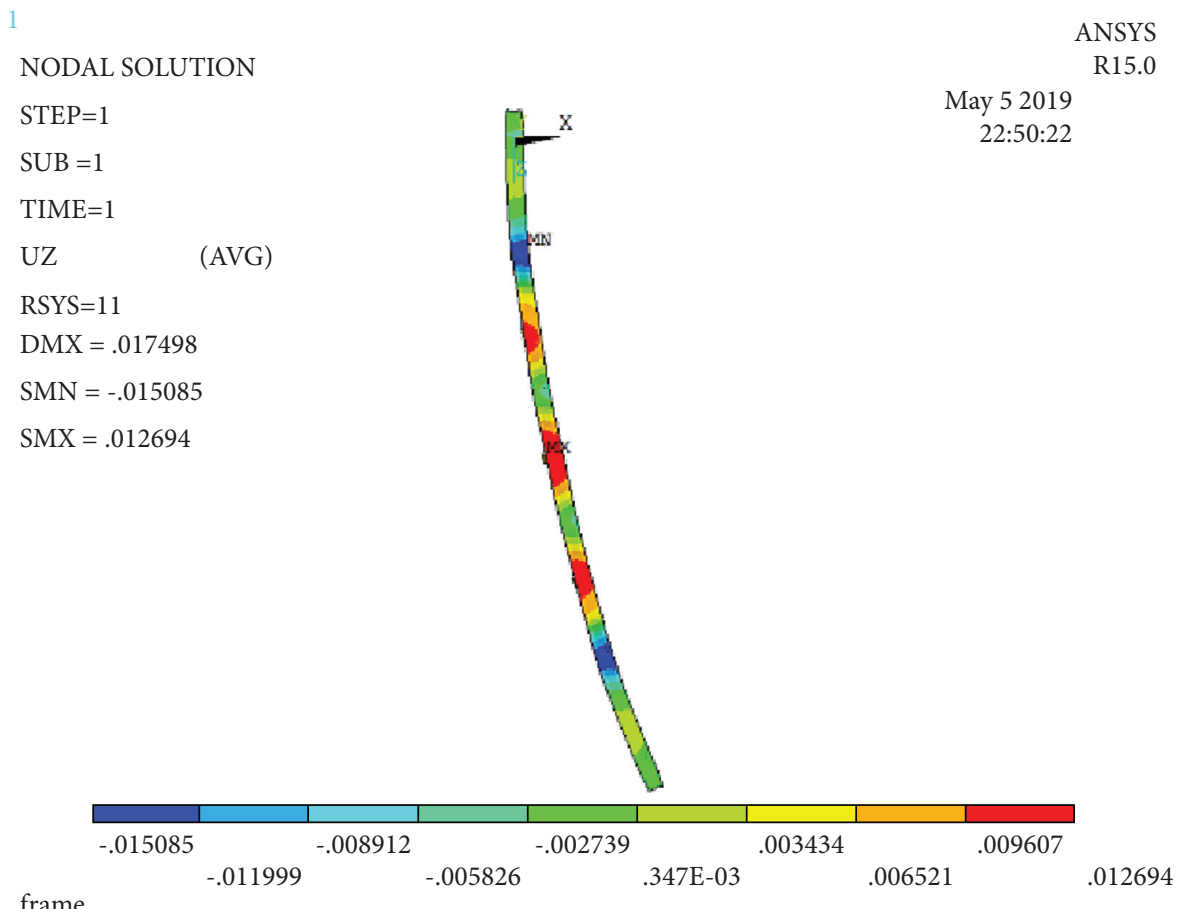

(a)

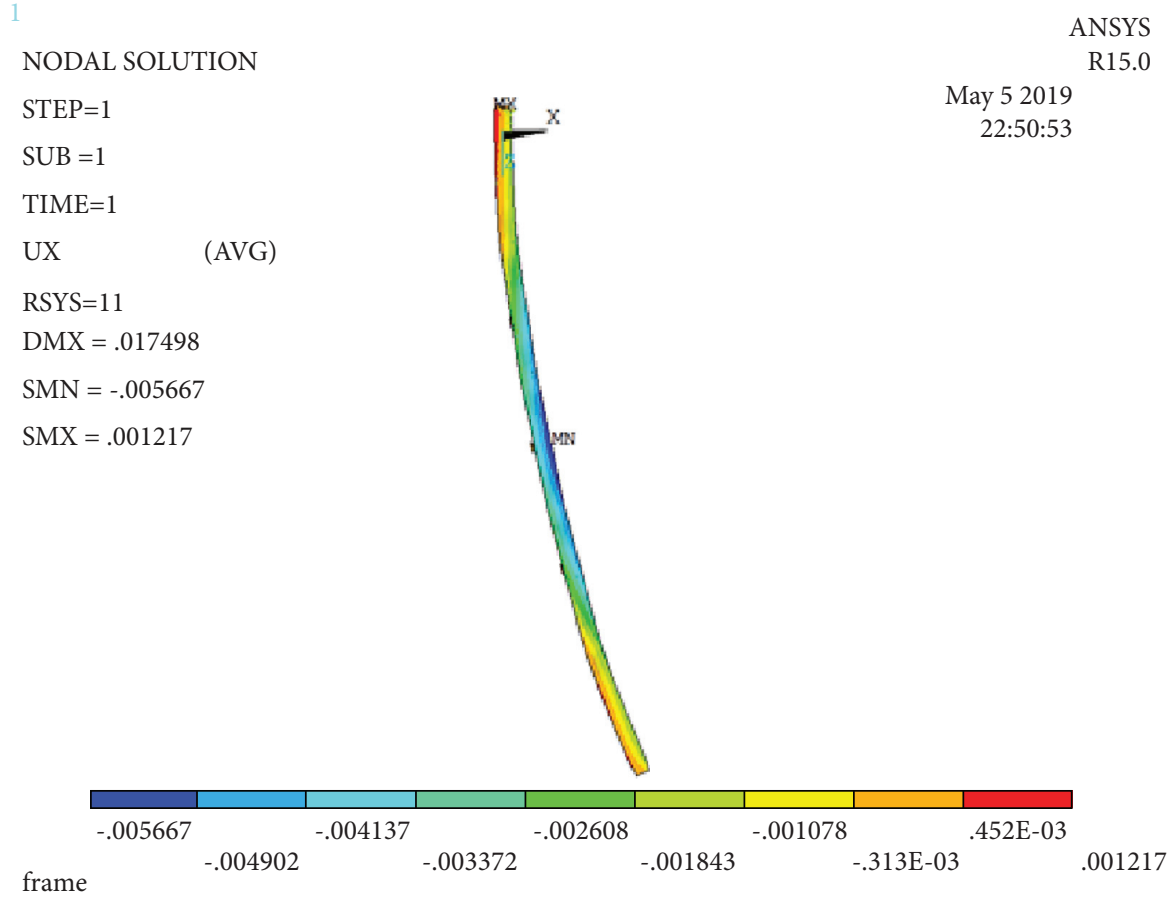

(b)

Figure 1: Displacement diagram of the bridge under dead load (vertical displacement diagram of node a and lateral displacement diagrams of b): (a) node vertical displacement graph and (b) node lateral displacement graph.

is negative, the outer member of the curved bridge rotates as positive, and the inward bending is negative.

From the impact vertical displacement diagram of bridge $D$ under its own weight and dead load, it can be seen that the downward vertical displacement amplitude of the inner node is greater than that of the outer node, and the upward vertical displacement amplitude is as follows. Therefore, every span of the bridge bends inward. As shown in Table 3, under its own weight and dead load, the pelvic support is located on the \# 1 column of the D bridge and is horizontal, so the corresponding main beam is clamped vertically on the \# 1 column to move vertically, and the lateral displacement is 
TABle 3: Displacement of 1\#-4\# pier top under dead load (unit: m).

\begin{tabular}{lcc}
\hline Pier number & Vertical displacement & Lateral displacement \\
\hline 1 & $2.30 E-18$ & $-1.62 E-07$ \\
2 & $8.81 E-04$ & $-2.37 E-02$ \\
3 & $1.02 E-03$ & $-3.61 E-02$ \\
4 & $8.08 E-04$ & $-2.22 E-02$ \\
\hline
\end{tabular}

almost no exist. The bridge pier beam between $2 \#-4 \#$ is integrated with the main girder of the $\mathrm{D}$ bridge, and the main girder joints on the top of the column are all vertically and laterally displaced upward and laterally toward the inner side of the arch bridge.

3.1.2. Vertical Settlement of Pier Bottom. In the static structure, the vertical settlement of the column will not produce any secondary stress, and the static structure bridge only undergoes spatial deformation without any internal force. In statically unsafe structures affected by the uneven vertical settlement of the columns, the bridge will not only produce spatial deformation but also generate secondary internal forces. Figure 2 shows the spatial deformation of bridge $\mathrm{D}$ when the piers are vertically settled.

It can be seen from Figure 2 that the vertical displacements of the inner and outer nodes of the main beam are consistent, and the vertical sinking of the column will not cause the main beam to twist. Under the action of vertical sinking, the corresponding main girder of $\mathrm{D}$-shaped bridge 1\# column top is supported vertically and horizontally, and the vertical and horizontal displacement is small.

\subsection{Analysis of Temperature Effect of Engineering Geomechanics}

3.2.1. Overall Temperature Change. The ambient temperature of the bridge changes slowly and steadily over a long period of time. When the ambient temperature changes, the entire bridge structure will have the same temperature change. In the finite element model, the total temperature rises and falls, and the structure is usually used for simulation. This study is based on an ambient temperature of $18^{\circ} \mathrm{C}$ and considers the changes in the spatial shape of the $\mathrm{D}$-shaped bridge when the main girder is raised or lowered by $12^{\circ} \mathrm{C}$, as shown in Figure 3 .

Figure 4 shows the displacement of the bridge under the influence of the overall cooling of the main girder.

It can be seen from Figures 3 and 4 that under the influence of the total heating and cooling of the main girder, the spatial change direction of the $\mathrm{D}$ bridge is opposite and the values are the same. As shown in Table 4, the main girder corresponding to the $\mathrm{D}$ 1\# bridge top is subject to vertical and horizontal restrictions under the influence of the total temperature rise and decline of the main girder, and there is almost no lateral displacement in the vertical and horizontal restrictions. Under the influence of the total heating of the main girder, the 2\#-4\# beam reinforcement column has vertical downward displacement and lateral displacement on the corresponding main girder. Under the influence of the overall cooling of the main girder, the column corresponds to the main beam and moves vertically upward and laterally inward.

\subsection{CFRP-Reinforced Structure Analysis}

3.3.1. Strain Changes. Figure 5 shows the effect of natural exposure time on the bonding behavior of the FRP-concrete interface, showing the elongation of CFRP and BFRP along the bond length under different loads. The horizontal axis represents the distance from the strain gauge to the span center, and the vertical axis represents the strain value.

When the loading begins, only the first and second strain gauges show strain readings near the center of the span. In addition, the value of the first strain gauge closest to the center of the span is much higher than the value of the second strain gauge. As the stress increases, the FRP stress begins to appear at the far end, and the stress near the center increases sharply. When FRP peels off in the middle of the span, the interfacial tension is redistributed, and the elongation at the other end reaches its maximum value. At this time, the FRP has completely peeled off the concrete surface. When the applied load is close to the ultimate load, the strain value far from the center of the field is very small, indicating that the ultimate load of the specimen does not increase with the increase of the bonding length of FRP.

3.3.2. Bond Stress-Slip Relationship. According to the data in Figure 5, the bilinear coupling stress-slip curve of the sample can be adjusted for different exposure times. As shown in Figure 6, as the exposure time increases, these points can be adjusted to the rising and falling levels of the model to obtain the bond stress-slip relationship between the CFRP-concrete interface and the BFRP-concrete interface.

3.4. The Influence of CFRP-Reinforced Structure Stress Distribution. Figure 7 shows the comparison between the theoretical calculation results and the experimental results of the test piece N-CFRP-180. The results show that the interface shear stress distribution of the two results is similar at all stages. As the load increases, the interfacial tension undergoes a rising and falling phase, and the rate of change has a constant difference. Compared with the experimental results, the theoretical calculation results are more evenly distributed far away from the loading position, which is mainly due to the continuity of the theoretical model assumptions.

By substituting the bond stress-slip ratio of the specimen under different exposure times $(0,180$, and 360 days) into the calculation process, the bond shear stress distribution along the bond longitudinal direction under different loads is obtained, as shown in Figure 8.

It can be seen from Figure 8 that, at the beginning of loading, the bond stress at the FRP-concrete interface near the center of the field is higher, and the shear stress in other areas is close to zero. This indicates that the interfacial shear tension is mainly concentrated in the center of the span and is not 


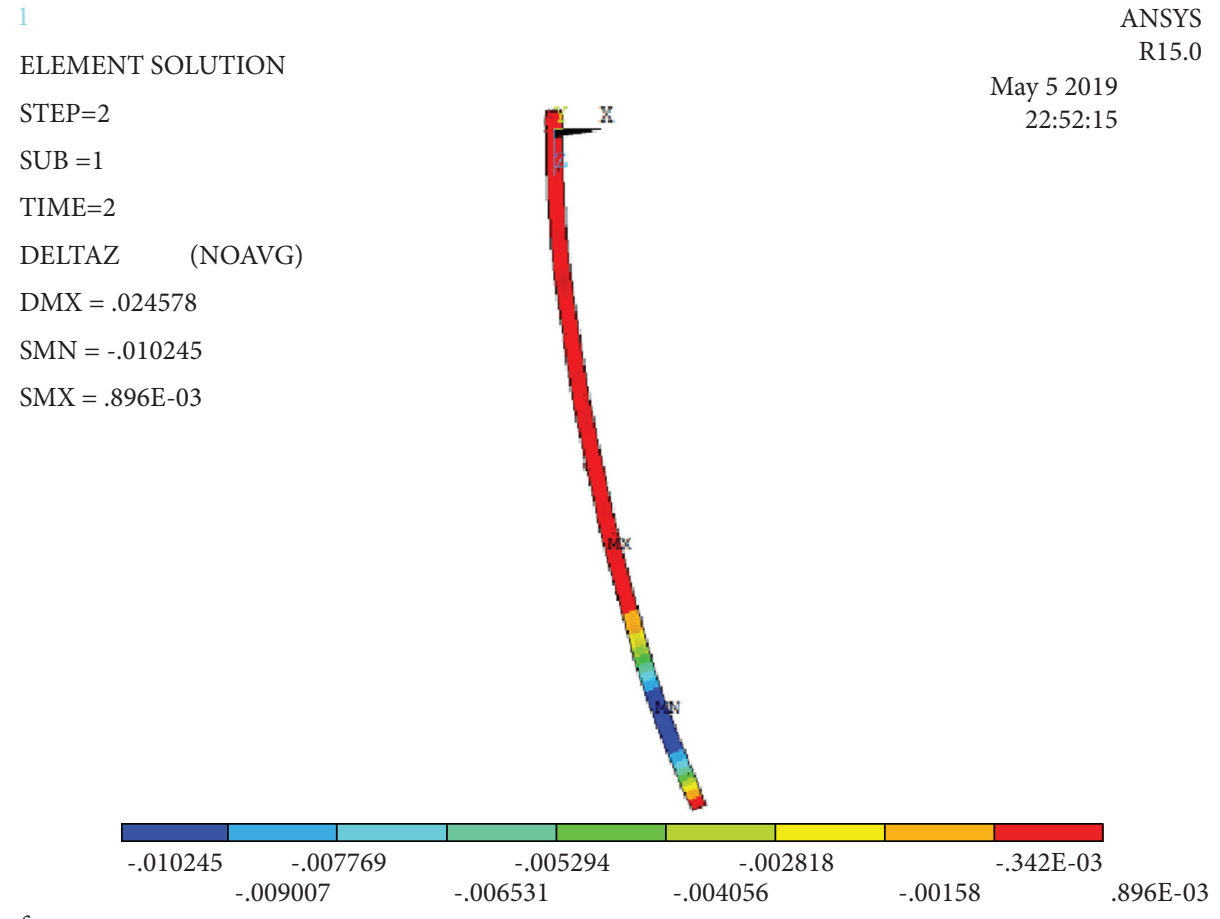

frame

(a)

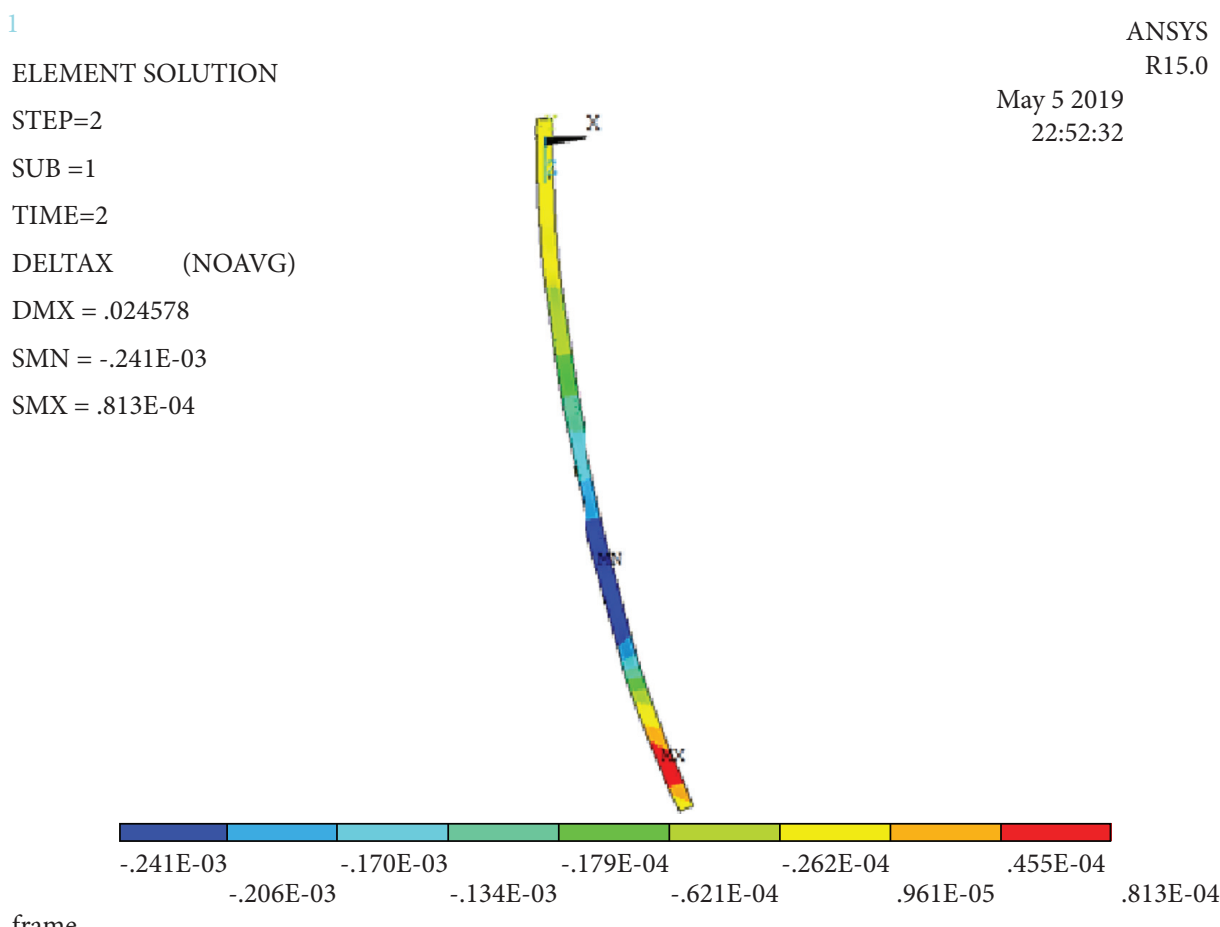

(b)

Figure 2: 2\# Bridge displacement diagram under the action of pier settlement $0.01 \mathrm{~m}$ (vertical displacement diagram of node a lateral displacement diagram of node b): (a) node vertical displacement graph and (b) node lateral displacement graph.

transmitted to the distal end. As the load slowly increases, the position of maximum coupling stress moves backward, and shear stress begins to appear at the distal end. Under different natural load times, the nodal tension in the direction of the entire FRP node indicates that the more the maximum nodal load position moves backward, the longer the natural load time. This indicates that the behavior of the FRP-concrete interface is weakened by the effects of natural exposure. 


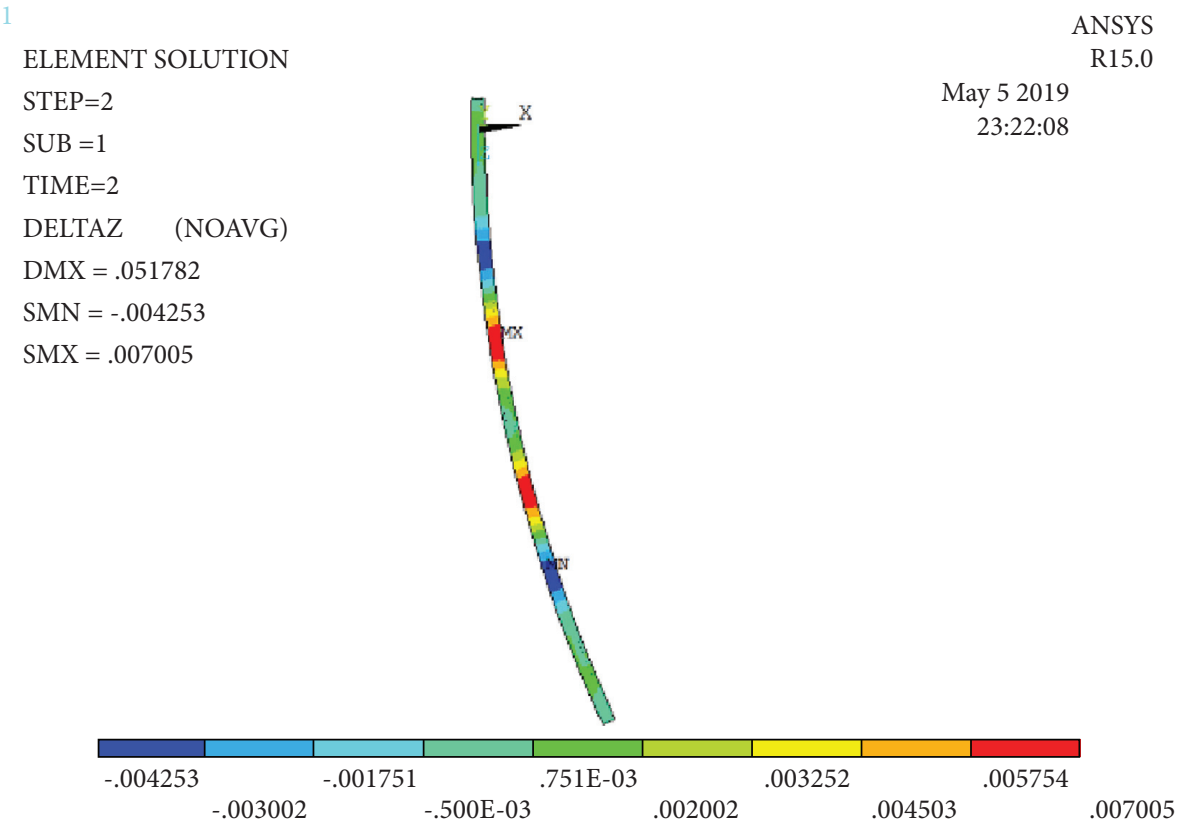

frame

(a)

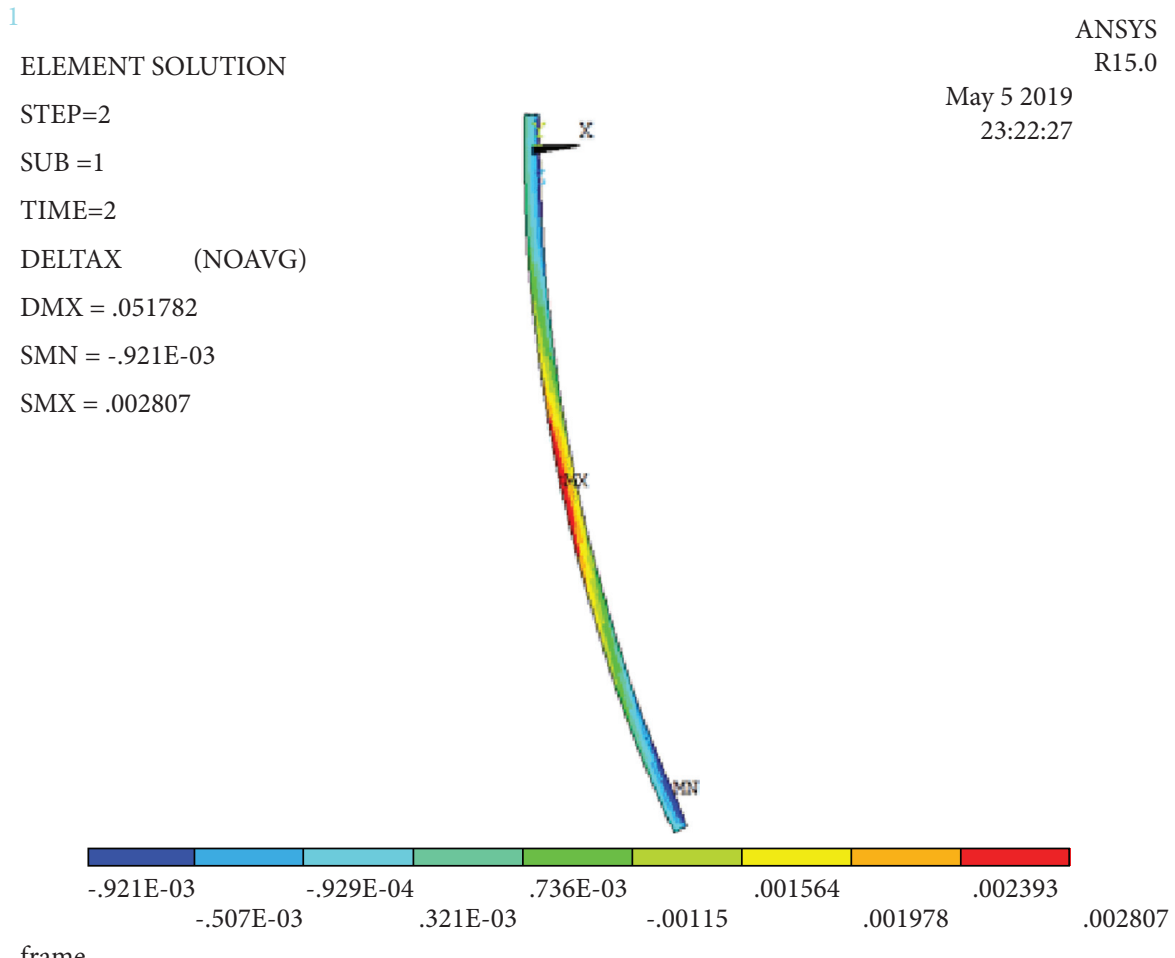

(b)

FIGURE 3: Bridge displacement diagram under the effect of the overall heating of the main girder (vertical displacement diagram of node a lateral displacement diagram of node b): (a) node vertical displacement graph and (b) node lateral displacement graph.

\section{Discussion}

4.1. Engineering Geomechanics Characteristics Analysis Technology. The ability of a bridge to deform under load is an important parameter for evaluating the structural stiffness of the bridge during operation. Bridge deformation can be divided into two aspects: local deformation and overall deformation. Local deformation refers to the stress and strain of bridge components that are usually detected by strain sensors. The overall deformation reflects the overall 


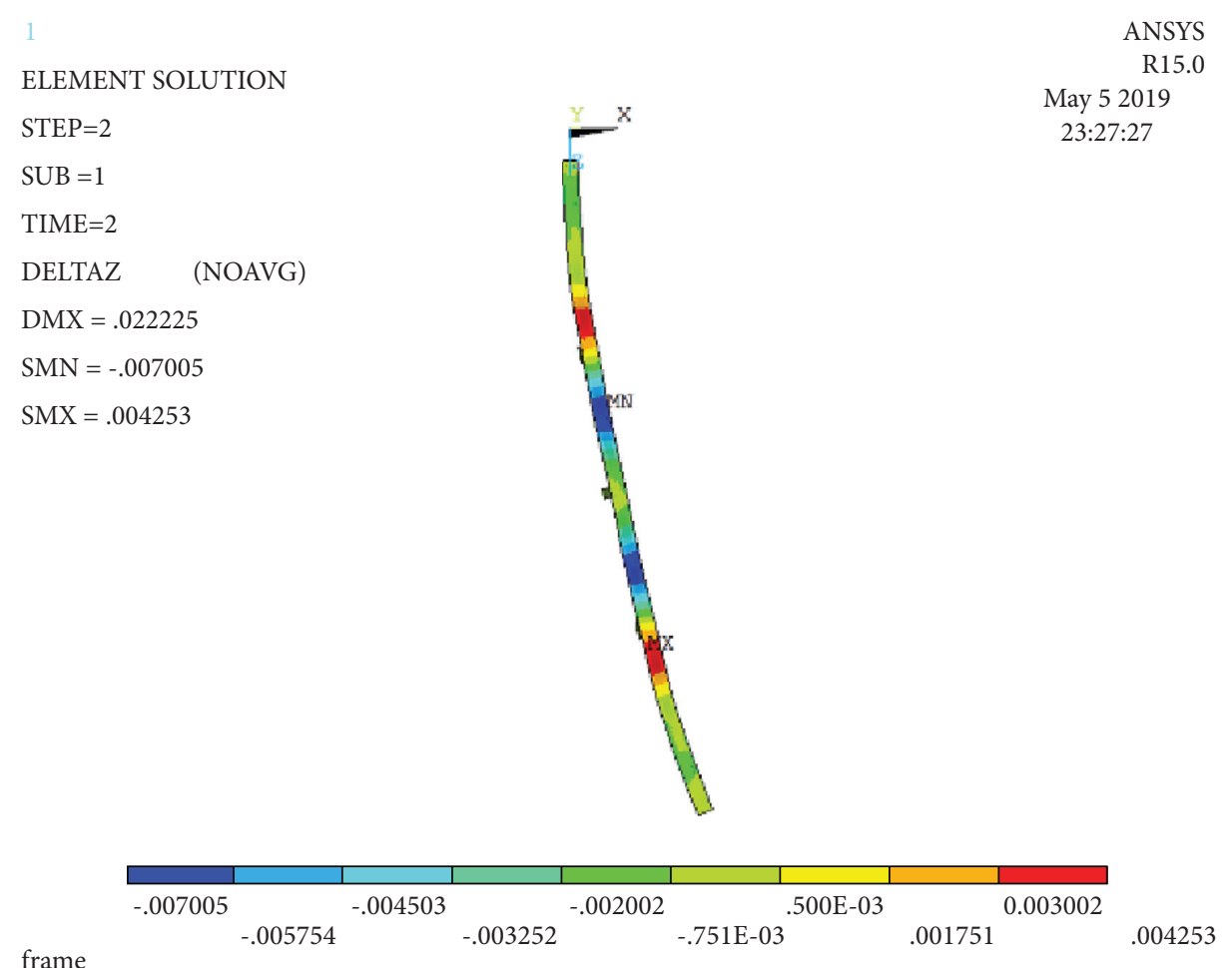

(a)

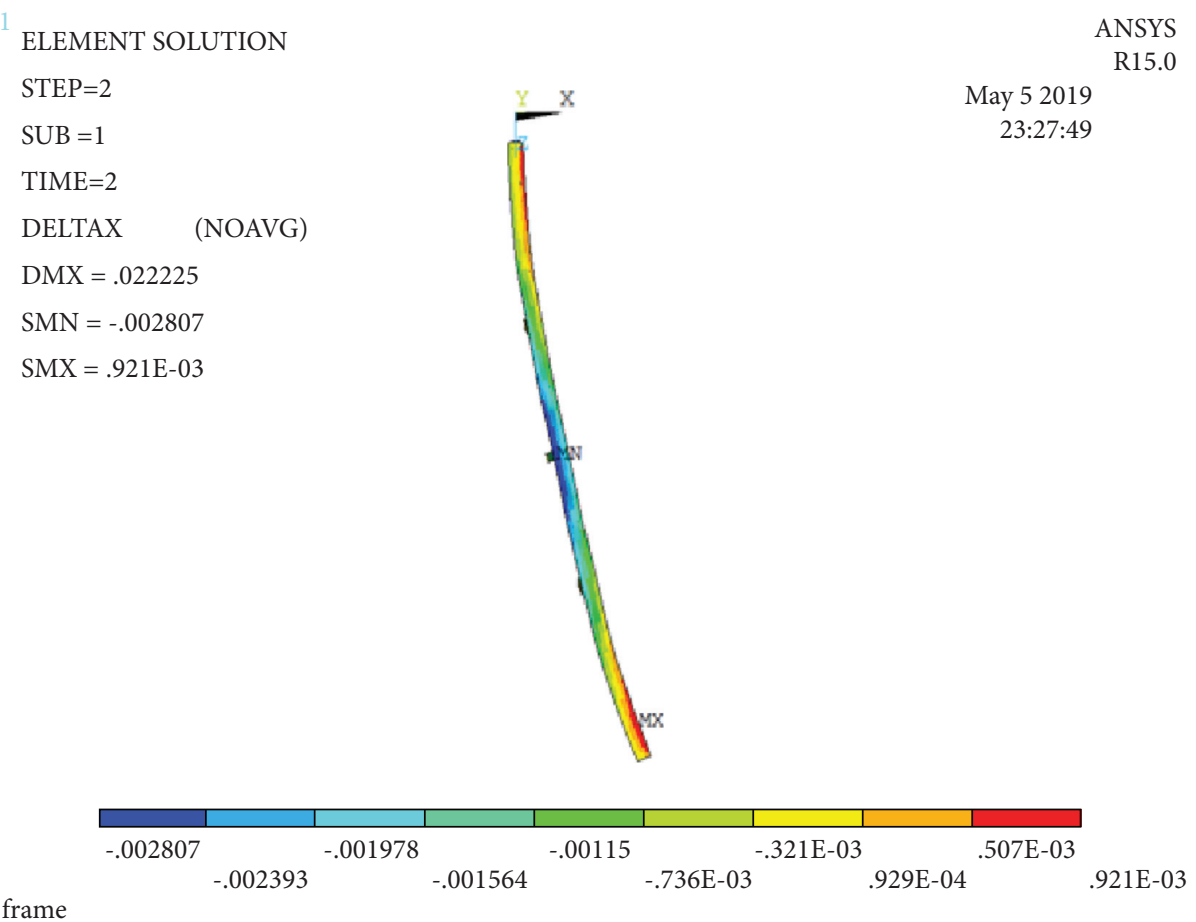

(b)

FIGURE 4: Bridge displacement diagram under the effect of overall cooling of the main girder (vertical displacement diagram of node a lateral displacement diagram of node b): (a) node vertical displacement graph and (b) node lateral displacement graph.

operating conditions of the bridge structure. The content of bridge deformation detection mainly includes main girder deflection, main girder vertical displacement, main girder lateral displacement, and main girder tip displacement.
In recent years, bridge deflection measurement methods based on digital imaging technology have developed rapidly. Compared with other deflection measurement methods, this technology does not require the installation of sensors. By 
TABLE 4: Displacement of the top of pier 1\#-4\# under the effect of the overall temperature rise and fall of the main beam (unit: $\mathrm{m}$ ).

\begin{tabular}{|c|c|c|c|c|}
\hline \multirow{2}{*}{$\begin{array}{l}\text { Working condition } \\
\text { Pier number }\end{array}$} & \multicolumn{2}{|c|}{$\begin{array}{c}\text { The overall temperature of the main beam is } \\
\text { increased by } 12^{\circ} \mathrm{C}\end{array}$} & \multicolumn{2}{|c|}{$\begin{array}{l}\text { The overall temperature of the main beam is } \\
\text { reduced by } 12^{\circ} \mathrm{C}\end{array}$} \\
\hline & Vertical displacement & Lateral displacement & Vertical displacement & Lateral displacement \\
\hline 1 & $6.23 E-20$ & $-4.44 E-07$ & $-6.25 E-18$ & $4.42 E-09$ \\
\hline 2 & $-1.33 E-05$ & $1.05 E-02$ & $1.35 E-03$ & $-1.03 E-04$ \\
\hline 3 & $-1.16 E-05$ & $1.99 E-02$ & $1.18 E-03$ & $-1.97 E-04$ \\
\hline 4 & $-1.31 E-05$ & $8.45 E-03$ & $1.33 E-03$ & $-8.43 E-05$ \\
\hline
\end{tabular}

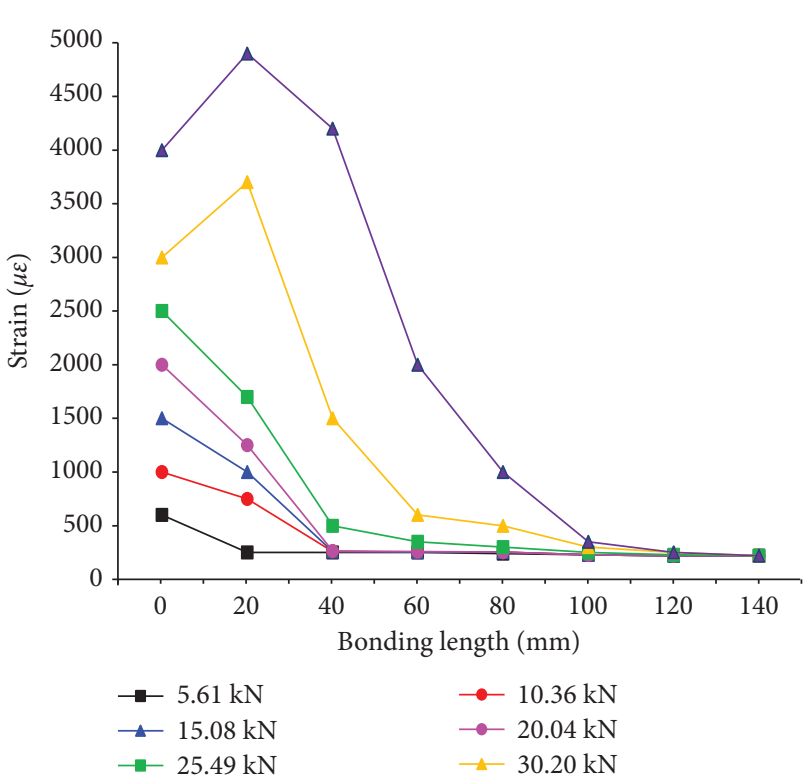

FIGURE 5: CFRP-reinforced control specimen.

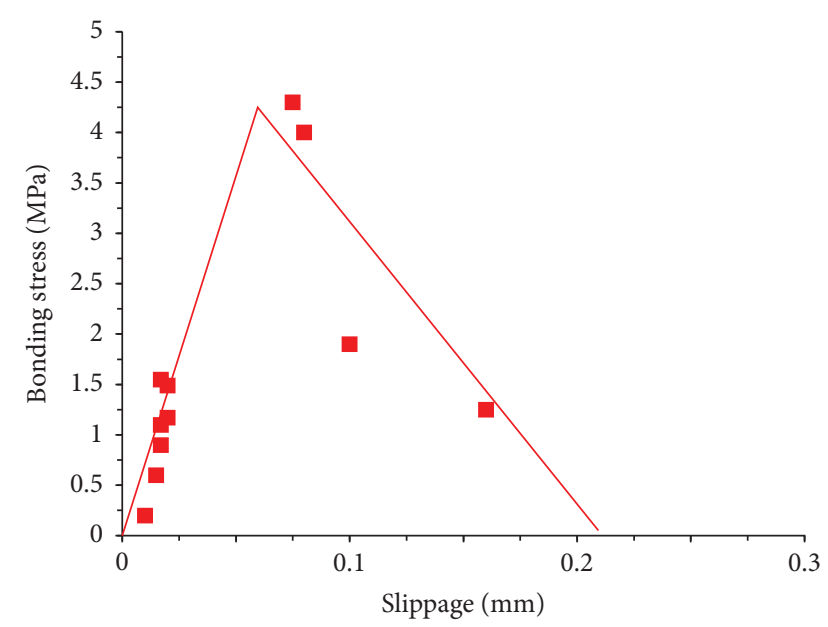

FIGURE 6: CFRP-reinforced control specimen.

comparing the digital images before and after the deformation of the structure, the structure displacement information is obtained to achieve long-distance noncontact measurement. It can be performed at high speed. It is the current bridge load test and the relative deflection of other buildings. There is a new method of change experiment. Digital imaging technology usually needs to first obtain 3D coordinate data based on image information and then perform the next step of the analysis. The 3D laser scanning technology can directly obtain the 3D coordinate data of the physical structure, which simplifies the data analysis process and reduces the error.

\subsection{CFRP Reinforcement Model Analysis Principle}

4.2.1. Selection of Concrete Failure Criteria. The actual performance and strength of concrete materials is a very complex issue. In the current concrete finite element analysis, a certain order of magnitude of concrete volume is generally regarded as a unit, as a continuous and uniform isotropic material. At this stage, scientists at home and abroad have proposed two 3D concrete failure standards. (1) The viewpoints used by the classical strength theory and the calculation formula standards of the classical strength theory are the Drucker-Prager strength standard and the Von Mises strength standard. (2) The more common multiparameter strength standards, are Bresler-Pister error standards, WilliamWarnke error standards, etc. This article uses ANSYS 2018 software for finite element analysis, so the Drucker-Prager strength standard is used.

4.2.2. Treatment of Concrete Cracks. The current finite element analysis can be divided into three commonly used concrete crack models: (1) individual crack models, (2) special unit models, and (3) scattered crack models. The advantage of the distributed crack model is that it does not increase the number of elements and the number of nodes, which is convenient for the realization of the finite element program. Therefore, the ANSYS finite element analysis adopts the diffusion crack model in this paper.

4.2.3. Bonding Treatment between Steel Bar and Concrete in Concrete Finite Element Analysis. In the existing finite element analysis, the two most commonly used methods for simulating the sliding of the steel bar and the concrete joint are as follows. (1) Method one is to add a fastener between the concrete and the steel bar to reflect the combined slip relationship. (2) Method two is to use material equation fitting to indirectly consider the effects of adhesion and slip. This method is simple and easy to use, without affecting the grid spacing, the calculation time convergence effect is good, and the result is high in accuracy, so this work uses this reinforced concrete pouring method. 


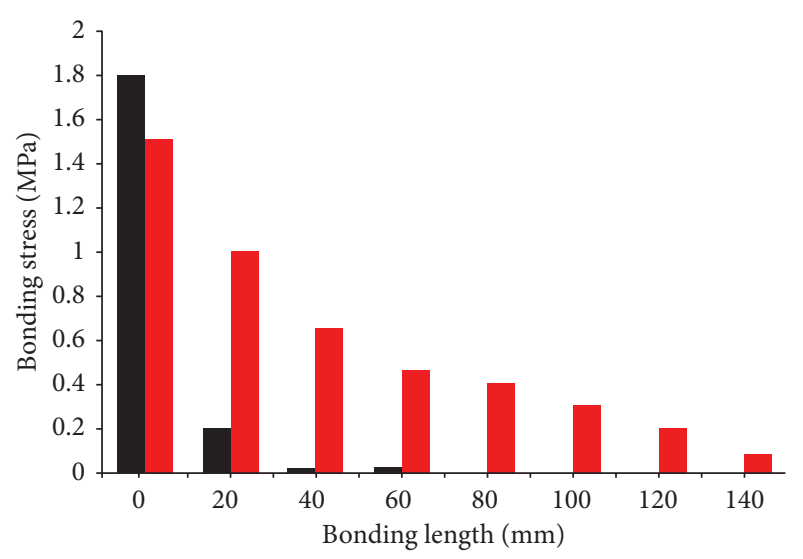

- experimental data when the load is $5.40 \mathrm{KN}$ n theoretical results when the load is $5.40 \mathrm{KN}$

(a)

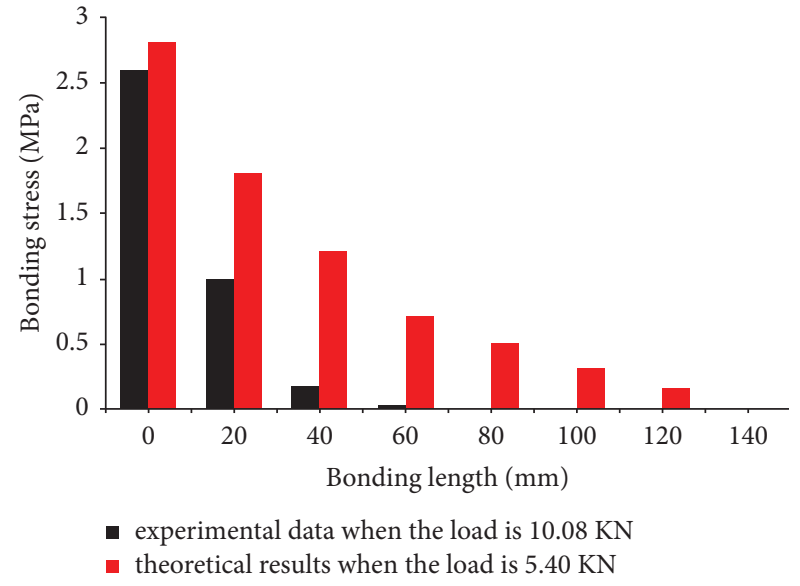

(b)

FIgURE 7: Comparison of theoretical results and experimental results of the N-CFRP-180 test piece: (a) $p=5.4 \mathrm{kN}$ corresponding bond stress and (b) $p=10.08 \mathrm{kN}$ corresponding bond stress.

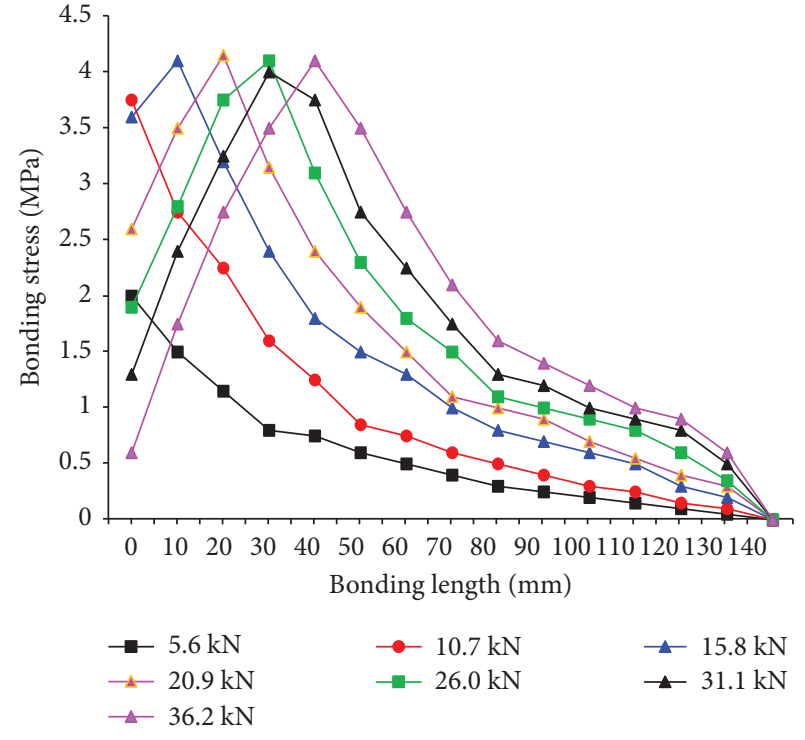

FIgURE 8: Theoretical results of the bond shear stress distribution at the interface of the specimen during the loading process.

4.3. CFRP Reinforcement Model Analysis Purpose. It is very expensive to replace all hidden bridges, and the roads need to be closed when the bridges are replaced. Studies have shown that the cost of building a new bridge is relatively high, and the cost of strengthening a bridge is at least $10 \%$ of that of a new bridge. Relatively speaking, it is cheaper to use reinforcement and repair than to build a new one, and on the other hand, it is more efficient. Therefore, under the premise of minimizing bridge damage, aging, and improving bridge life, in a broad sense, strengthening and repairing bridges has important economic and social benefits.

Although CFRP paste reinforcement technology is common, the disadvantage of this passive reinforcement technology is that it does not have the high-strength performance of CFRP materials, and the reinforcement components only work after secondary stress. It is used in most scientific research and engineering technology and is recognized by the person in charge. In order to make up for the shortcomings of this technology, prestressed CFRP reinforcement technology was temporarily introduced, imitating the technical idea of prestressed steel bars/strands. It can participate in the force (effective force) before the second force is applied to the reinforced component and change the stress distribution of the reinforcing element to close the original crack or prevent its expansion. Therefore, the prestressed CFRP reinforcement technology is more and more favored by traffic and civil engineering engineers. The use of prestressed CFRP reinforcement technology has become widespread in practice. Under actual operating conditions, the long-term mechanical properties of prestressed CFRP-reinforced concrete (RC) components have also attracted more and more attention. RC bridge reinforcement structure is used for natural exposure environment. During operation, due to concrete shrinkage and creep, performance degradation, and CFRP-concrete interface mechanical performance degradation, the prestress is lost, resulting in the long-term mechanical performance of prestressed CFRPreinforced RC structure deterioration. Under this engineering background, this article takes prestressed CFRP-strengthened $\mathrm{RC}$ beams as the research object to investigate the long-term mechanical properties under natural exposure environments and provides a scientific basis for the application of prestressed CFRP technology in engineering practice. The wide application of concrete structure in engineering has caused its safety and stability to attract much attention. At present, various countries in the world have carried out different degrees of research topics on material reinforcement methods. The research in this area in our country is still in its infancy, and the research has been less successful. The application in actual engineering has not been widely developed, and there are still many problems to be solved. Theoretical research needs to be further strengthened and effectively applied to actual projects. Starting from the reliability theory, feasible regulations and standards are formulated to guide practice. 


\section{Conclusion}

Aiming at a typical long bridge, this paper evaluates the early warning of the damage of the long bridge through a machine learning algorithm designed for material parameter selection and test beam conditions. The research analysis used mainly includes three types of analysis: mechanical analysis corresponding to rigid body displacement at the structural level, mechanical analysis corresponding to rigid body displacement at the component level, and mechanical analysis corresponding to internal changes. Whether it is the CFRPconcrete interface or the BFRP-concrete interface, their adhesion properties deteriorate with the prolonged exposure time. By analyzing the engineering geomechanical characteristics under the influence of the overall heating and cooling of the main girder, the spatial direction of the $\mathrm{D}$ bridge is opposite and the value is the same. In the static structure, the vertical settlement of the column will not produce any secondary stress, and the static structure bridge only undergoes spatial deformation without any internal force. In statically unsafe structures affected by the uneven vertical settlement of the columns, the bridge will not only produce spatial deformation but also generate secondary internal forces. From the vertical displacement of the D bridge node under its own weight and dead load, it can be seen that the amplitude of the downward vertical displacement of the inner node is greater than the amplitude and the vertical amplitude of the outer node. The upward displacement is less than the displacement of the outer nodes, so all spans of the bridge are equal to inward bending. The wide application of concrete structure in engineering has caused its safety and stability to attract much attention. At present, various countries in the world have carried out different degrees of research topics on material reinforcement methods. The research in this area in our country is still in its infancy, and the research has been less successful. The application in actual engineering has not been widely developed, and there are still many problems to be solved. Theoretical research needs to be further strengthened and effectively applied to actual projects. Starting from the reliability theory, feasible regulations and standards are formulated to guide practice.

\section{Data Availability}

The dataset can be accessed upon request.

\section{Conflicts of Interest}

The authors declare that there are no conflicts of interest.

\section{References}

[1] I. S. Asaad and M. F. Omer, "Facies characterization and depositional environment of baluti formation (late triassic) from selected sections in the kurdistan region, northern Iraq," Arabian Journal of Geosciences, vol. 13, no. 23, p. 1253, 2020.

[2] I. Aarab, M. Derqaoui, A. Abidi et al., "Direct flotation of lowgrade Moroccan phosphate ores: a preliminary micro- flotation study to develop new beneficiation routes," Arabian Journal of Geosciences, vol. 13, no. 23, p. 1252, 2020.

[3] H. Atapour and M. Moosavi, "Some effects of shearing velocity on the shear stress-deformation behaviour of hard-soft artificial material interfaces," Geotechnical \& Geological Engineering, vol. 31, no. 5, pp. 1603-1615, 2013.

[4] M. Bahaaddini, P. C. Hagan, R. Mitra, and B. K. Hebblewhite, "Parametric study of smooth joint parameters on the shear behaviour of rock joints," Rock Mechanics and Rock Engineering, vol. 48, no. 3, pp. 923-940, 2015.

[5] M. Bahaaddini, P. C. Hagan, R. Mitra, and M. H. Khosravi, "Experimental and numerical study of asperity degradation in the direct shear test," Engineering Geology, vol. 204, pp. 41-52, 2016.

[6] J. Cheng, X. W. Xu, W. J. Gan, W. T. Ma, W. T. Chen, and Y. Zhang, "Block model and dynamic implication from the earthquake activities and crustal motion in the southeastern margin of Tibetan Plateau," Chinese Journal of Geophysics, vol. 55, no. 4, pp. 1198-1212, 2012.

[7] Y. Cui, "Effect of joint type on the shear behavior of synthetic rock," Bulletin of Engineering Geology and the Environment, vol. 78, no. 5, pp. 3395-3412, 2019.

[8] F. Duriyapong and K. Nakhapakorn, "Coastal vulnerability assessment: a case study of Samut Sakhon coastal zone," Songklanakarin Journal of Science and Technology, vol. 33, no. 4, pp. 469-476, 2011.

[9] C. Gehle and H. K. Kutter, "Breakage and shear behaviour of intermittent rock joints," International Journal of Rock Mechanics and Mining Sciences, vol. 40, no. 5, pp. 687-700, 2003.

[10] F. Hallouz, M. Meddi, G. Mahé, S. Alirahmani, and A. Keddar, "Modeling of discharge and sediment transport through the SWAT model in the basin of Harraza (Northwest of Algeria)," Water Science, vol. 32, no. 1, pp. 79-88, 2018.

[11] Z. M. He, Z. Y. Xiong, Q. G. Hu, and M. Yang, "Analytical and numerical solutions for shear mechanical behaviors of structural plane," Journal of Central South University, vol. 21, no. 7, pp. 2944-2949, 2014.

[12] H. Jahanian and M. H. Sadaghiani, "Experimental study on the shear strength of sandy clay infilled regular rough rock joints," Rock Mechanics and Rock Engineering, vol. 48, no. 3, pp. 907-922, 2015.

[13] E. Z. Lajtai, "Shear strength of weakness planes in rock," International Journal of Rock Mechanics and Mining Science \& Geomechanics Abstracts, vol. 6, no. 5, pp. 499-515, 1969.

[14] E. Z. Lajtai, "Strength of discontinuous rocks in direct shear," Géotechnique, vol. 19, no. 2, pp. 218-233, 1969.

[15] M. A. Saleh, "Mangrove vegetation on abu minqar island of the red sea," International Journal of Remote Sensing, vol. 28, no. 23, pp. 5191-5194, 2007.

[16] T. S. Sankari, A. R. Chandramouli, K. Gokul, S. S. M. Surya, and J. Saravanavel, "Coastal vulnerability mapping using geospatial technologies in Cuddalore-Pichavaram coastal tract, Tamil Nadu, India," Aquatic Procedia, vol. 4, pp. 412418, 2015.

[17] F. G. Xue, P. S. Julian, and M. H. Chris, "Direct shear test of sandstone-concrete joints," International Journal of Geomechanics, vol. 3, no. 1, pp. 21-33, 2003.

[18] J. B. Zhu, H. Li, and J. H. Deng, "A one-dimensional elastoplastic model for capturing the nonlinear shear behaviour of joints with triangular asperities based on direct shear tests," Rock Mechanics and Rock Engineering, vol. 52, no. 6, pp. 1671-1687, 2019. 